\title{
Review on Emerging water Borne disease
}

Rameetha. R, Abhay Kumar

Water Quality Research Centre, Eureka Forbes Institute of Environment, Bangalore, Karnataka, India rameetha1984@gmail.com, abhay@eurekaforbes.com

\section{ABSTRACT:}

Every year the cases of water borne infection through out the world are increasing. If we check the motto behind every Government the main aim will be evading the water borne infection and also to reduce toll death rate due to the water related infection. This mission has been started long back and still we are not able to meet the motto. This review focuses on the emerging pathogens its habitat and the case history which gives a clear view about how this can poses problem to the future generations.

\section{Indexing terms/Keywords}

Water related disease; infection; bacterial; emerging pathogen; water borne infections.

\section{Academic Discipline And Sub-Disciplines}

Biotechnology

SUBJECT CLASSIFICATION

Microbiology

TYPE (METHOD/APPROACH)

Review Article

\section{Council for Innovative Research}

Peer Review Research Publishing System

\section{Journal: JOURNAL OF ADVANCES IN BIOTECHNOLOGY}

Vol .3, No 1.

www.cirjbt.org , jbteditor@gmail.com 


\section{INTRODUCTION}

Water borne disease is a broad term, in which the microbes play a major role. The common terms in the history of water borne disease are E.coli, Vibrio, and Coliforms etc. Many bacterial diseases fall in the category of re-emerging disease due to the resistance to antibiotics (Louis H.Nel \& Wanda Markotter). If we see our history there is lot of changes with new technologies and updated knowledge. Does this changes effect the pattern of microbiological contamination. May be YES. Most of them have a concept that water borne disease means through drinking water only, but there are many ways which can cause disease through water. As per World Development report in 1992 the Diarrheal diseases cases was estimated has $900,000,000$ per year and approximately and toll death rate in case of children has reached to $2,000,000$ deaths per year in children (World Development report 1992). In US between 1920 -1992 toll rates of 1,786water borne outbreak with 472, 228 cases of illness and 1,091 deaths. (Harry Philippeaux et al). If we check the surveys the water borne disease is increasing day by day and the symptoms also varies from place to place. In earlier days E.coli also was reported as a rare case of infectious organism, but later E.coli became a general term of infection. There are many pathogens which includes marine bacteria, enteric bacteria, and protozoans etc which are resistant to most of the filtration and disinfection process.

The present review is about the emerging bacterial infection in which the source of infection is water. The water can be a direct or indirect source but in future this can pose serious issue.

\section{Aeromonas hydrophila (flesh eating bacteria):}

Aeromonas hydrophila is ubiquitous in water. They are hetrotropic gram negative aerobic, non sporing bacilli which are mainly found in the warmer climate. The optimal temperature for growth is $28^{\circ} \mathrm{C}$ with a wide range of temperature ranging from $4^{\circ} \mathrm{C}-37^{\circ} \mathrm{C}$. The habitat is mainly aquatic environment such as lakes ponds, rivers, fresh water \& brackish water, although it has been isolated from fish tank, swimming pool and chlorinated water. This species are resistant to chlorine treatment, so that it can survive even after the chlorine treatment. Mode of transmission is generally through feaco oral, or the contact with the contaminated water, food and it can also enter through open wounds. The symptoms starts developing after $48 \mathrm{hr}$ of infection with the formation of cellulitis which may later develop into skin necrosis fascitis, fruncles and nodule formation in the skin. It can also be associated with the gastroenteritis, mild to moderate soft tissue infections. (Kenji Okumura et al 2011). A recent review says that Holy water is a potential source of cross-infection with various coliform bacteria, including A. baumanii and Aeromonas hydrophila (Rees JC et al 1996).

A.hydrophilia occurrence has been ruled out in early 1980 's to cause infection in fish and reptiles and later it also proved that the Aeromonas hydrophila is responsible for causing diarrhea in humans. (Samuel.A.Palumbo et al 1985). It has been isolated from polluted and non polluted water throughout the world.(Schubert,1975).It is also associated with corneal ulceration, endophtalmitis, osteomyelitis, septic arthritis, endocarditis, peritonitis, biliar obstruction and colecistitis, intraabdominal abscesses, urinary infections, otitis media (Khardori and Fainstein, 1988). In US it reported that in summer the Aeromonas spp. is found in the faeces and in the tap water, and also the USA protection agency has listed the Aeromanas Hydrophilia in there contamination list has emerging pathogen in Drinking water (MM Aslani \& MY Alikhani2004).

\section{Mycobacterium Chelonae}

M. chelonae are gram positive acid fast bacilli which grow rapidly. It is considered as the commensals in the humans. (Brown TH 1985). They are free living ubiquitous bacteria which are found in soil and water (Sanders et al 1990). They are found in natural and processed water sources including sewage and in tap water. Environmental mycobacteria such as $\mathrm{M}$. chelonae can resist temperatures of $45^{\circ} \mathrm{C}$ and some disinfectants such as $2 \%$ alkaline glutaraldehyde. (Alfred $\mathrm{M}$. Emmerson 2001). The main causes of the outbreak has been reported by the exposure to non sterile water, inadequately disinfected or reusable instruments.(H-C. Wang et al., 1995). Hospital water supplies can readily become contaminated with environmental mycobacteria, e.g., M. xenopi, M. abscesses, M. fortuitum, and M. chelonae; if decontamination units do not have filters $(0.2 \mu \mathrm{m})$ fitted to the water supply, rinse water may become contaminated.(Alfred M. Emmerson2001)

Young people are crazy about Tattoos and are common in many countries. The infection behind the tattoo making is also common and it blames normally the needle or the unhygienic condition. But a rare case was seen in Newyork where the water is the base for the infection and the agent is Mycobacterium chelonae which is not life threatening but it causes painful pus filled blisters. The mode of infection here was the unsterilized or the tap water which is used to lighten the ink. Normally witch hazel or alcohol is being used to avoid the risk of bacterial infections but unfortunately this strain is resistant to most of the disinfectant. This may not be relevant in the Indian market but now days there are many youngsters in India who prefer tattoos and it's becoming most common, whatever precaution we take the ink can also be a source of infection. A report says the outbreak of M.chelonae infection followed by the liposuction was found and later the investigation proved that the portable water is the common cause of infection and the routes are due to the reuse of the liposuction tubing after washing with the tap water or the inadequate disinfection of infusion for handling for tumescent infusion solution (Hildy Meyers etal 2002)

Other Mycobacterial species are also responsible for the infection where the water acts has a major source of infection.

\section{Mycobacterium marinum}

Mycobacterium marinum is a gram positive bacteria acid fast bacteria which is widely distributed in aquatic environment especially in the stagnant water such as fish tank, swimming pool, and the incubation period ranges from 5 and 270 days.(Lucinda Elko et al 2003). The optimal growth temperature ranges from $28-32^{\circ} \mathrm{C}$. They are photochromogen which are capable of producing pigment when cultured and exposed to light.(Mark N Schwendiman et al 2009).M.marinum was first isolated first in 1926 By Arosonfrom from salt water fish that died in Philadelphia aquarium, Later in 1951 it was 
recognized to cause human infection by which was isolated from skin lesions in swimmer of contaminated swimming pool in Swedish town. In 1962 Swift and Cohen reported the first case of skin infection acquired from aquarium. (V. Caputo et al., 2010)

M.marium is capable of causing nonsystematic infections which is evident has granulomatous skin lesions. The route of infection is not clearly understood but it is most likely to cause infection through the cuts or wounds who gets exposed to the contaminated water. (Monica Hagedorn \& Thierry Soldati 2009). In deeper infection it causes infection such has tenosynovitis, septic arthritis and very rarely osteomyelitis. (Peter Van Seymortier et al.,2004). The lesions are most common on the elbows, knees and feet of swimmers and on the hand and fingers of fish franciers (V. Caputo et al,.2010).Cases were reported in case of the patients who had exposed their hands in the fish tank. The typical symptoms include the primary lesions typically blue red papule, nodule or plaque. In 2003 a 56 year male patient was ruled out with M.marinum infection with acute swelling and erythema on the proximal interphalangeal joint of the right middle finger. (Peter Van Seymortier et al., 2004) In 2008 it has been reported that this species was isolated from the patient who worked at fish Farm in Jiangsu Haian, China. (Feng Y et.al 2011)

\section{Salmonella Kottbus}

Salmonella Kottbus a gram negative bacteria in which most of the cases reported was infants below one year of age. A report says in 1996 there was an outbreak of S. kottbus which has affected around 46 infants and the cause of infection was ruled out later has bottle water infected with Salmonella kottbus. The average age of cases reported was five months. (R Palmera - Suarez et.al 2007). Another species associated with the bottle water outbreak is Salmonella bareilly which was detected through CDC's (CDC 2002).

\section{Chryseobacterium meningosepticum}

Chryseobacterium meningosepticum formerly known as Flavobacterium meningosepticum, a gram negative, non motile bacteria ubiquitous in water and soil. They are most prevalent in hospital environment due to the ability of the organism to grow in non nutrient media. This organism can survive in the chlorine treated water, sink basin, taps (Hyu sun Yoon 2007). This pathogen mainly associated with meningitis in premature and new borne babies and rarely causes pneumonia, endocarditis and meningitis associated with adults.(Shou-Wu Lee et al., 2008).

In 1996 a report says that Chryseobacterium meningosepticum was isolated from tap water of the neonatal ICU. Eight cases of the C.meningosepticum have been reported from Aug 2002 - Dec 2003 at Mauritius at Jawaharlal Nehru Hospital. This bacteria are resistant to most of the antibiotics used against gram negative bacteria such as aminoglycosides, $\beta$-lactam agents, Chloramphenicol, carbapenems, but susceptible to agents used to treat gram positive bacteria like Rifampicin, Ciprofloxacin, Vancomycin, trimethoprim-sulfamethoxazole.

\section{Chromobacterium violaceum:}

Chromobacterium violaceum is a saprophytic bacterium which was first discovered in 1905 by Wooley in water buffalo. Later in 1927 it was seen in humans also (Sneath PHA et al 1953). In humans C. violaceum results in systemic and severe disease ranging from cellulitis and skin abscess, which can later develop has sepsis and multiorgan abscess in lung, liver spleen. They are gram negative, non sporing bacteria measuring approximately about $0.5 \mu \mathrm{m}$ long and $2-3 \mu \mathrm{m}$ wide, which are the habitat of soil and water. There exhibit both pigmented and non pigmented strain where the infection

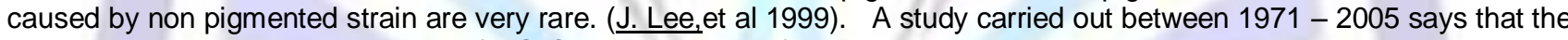
mortality rate is between $60 \%-80 \%$ (A G Orsetti, et al 2013). Infections occurs mainly via traumatic injury or by drinking contaminated water, and cellulitis or an abscess may or may not form at the site (Martinez R et al 2000, A G Orsetti, et al 2013).

Chromobacterium violaceum in which the source of infection is due to recreational activity, or it can also occur after the exposure of wounds to the stagnant water or soil. (Roberts SA et al 1997, Ender PT et al 1997) They are widely distributed in the nature and are sensitive to temperature. The infection pattern is again different by eating away the body tissue. The case history was interesting where an old man at the age of $42 y$ rs fell down from bike into a drainage canal and had injuries on head and $C$. violaceum was isolated from the wound, the symptoms developed was fulminating septicemia, with necrotizing metastatic lesions and multiple abscesses in the liver, lung, spleen, skin, lymph nodes, and brain, resulting in fatal multiorgan failure (Gunther Slesak et al 2009). C. Violaceum is usually susceptible to chloramphenicol, tetracycline, gentamicin, co-trimoxazole, ciprofloxacin and imipenem, and resistant to penicillins, cephalosporins and aztreonam (Ti TY et al 1993, Midani S et al 1998, Atapattu DN et al 2001). A first case of C. violaceum from coastal Karnataka has been reported in a $2 y r$ old girl (Mamatha Ballal et al 2000). These organism may be the rarest but in mere future we can find this in our drinking water because in many places our drinking water is getting mixed with the drainage water. As per the reports the infection by C.violaceum is rare but the mortality is very high and this is most predominantly seen in south eastern countries.

\section{Erysipelothrix rhusiopathiae}

Erysipelothrix rhusiopathiae thin, gram positive bacilli, non sporulating bacterium which was isolated by Koch in 1878 , (Koch, R. 1880, Annette. C. Rebolit And W. Edmund Farrar,1989) which causes erysipeloid. It is a zoonotic infection in humans caused mainly with meat and fish handlers. (Dean Campbell and Mark Cowan 2013)The habitat is aquatic and it can survive for long period in the fish slime. (R. L. Woodet al 1975) In case of humans the infection is very rare and it is found especially with fisher man. The mode of infection can be exposure of the infectious agent through the wound or by punctures where the incubation period ranges from 1-7 days with mild cutaneous infection termed has erysipeloid. In the 
severe cases it is associated with purpuric rash which is blue or purple with well raised border. (Dean Campbell and Mark Cowan 2013).

A report by Ramona Simionescu et al in 2003 reports that lady was manifested with narcotizing fasciitis where the source was reported has pet gold fish.

\section{Halomonas venusta}

Halomonas venusta, gram negative halophilic proteobacteria, non fermentative bacteria found in marine environment. H.venusta was first discovered by Baumann et al 1973(Alexander von Graevenitz et al 2000). This is also seen harboring in the fish and the fish acts as a mediator for spreading infection. The case history says a healthy women at the time of recreational activity was bitten by the fish which is infected with $\mathrm{H}$. venusta. Later the symptoms developed to a painful cellulitis with watery discharge (Alexander von Graevenitz et al 2000).

\section{Burkholderia pseudomallei}

Burkholderia pseudomallei causes Melioidosis with complex pathogenesis, the causative organism was first described by Whitmore in 1912 when he first isolated B. pseudomallei from an opiate addict in Rangoon. This is a gram negative bacilli resistant to many antibiotics such has Gentamicin and Colistin. An interesting thing about these bacteria is it can be seen as gram positive bacteria under environmental stress. B. pseudomallei is an environmental saprophyte isolated from wet soils, agricultural soils, streams, pools, stagnant water and, in particular, paddy fields throughout the endemic areas. (Air Vice-Marshal Bruce $\mathrm{H}$ Short 2002). This is normally found in rainy season and the most susceptible people are with the occupation such has farmers, construction people travelers and the through recreational activity. The clinical symptoms may vary from person to person and severity also varies. The patients may suffer from rapidly fatal septicemic illness without pneumonia to focal abscess. Other clinical manifestation includes acute form, spreading fulminant sepsis. The most common symptoms are bacteriemia,pneumonitis, pulmonary, splenic, hepatic and cutaneous abscesses.One of the biggest drawback of this infection is the sudden death or death within two days of infection.

The first case of human melioidosis in Australia was described in a young diabetic adult from Towns ville in 1950 who died of septicemic melioidosis (Remington RA 1962). Six melioidosis cases were identified from the 2004 tsunami survivors. (Wirongrong Chierakul et al 2005) in Southern Thailand. The case history says in Singapore in early 1990`s there was sudden death in the construction sites where later ruled out has Melioidosis infection. The average mortality rate from melioidosis over the study period was $42.6 \%$. The minimum estimated population mortality rate from melioidosis in 2006 was 8.63 per 100,000 people $(95 \% \mathrm{Cl}=7.33-10.11)$, the third most common cause of death from infectious diseases in northeast Thailand after human immunodeficiency virus (HIV) or acquired immunodeficiency syndrome (AIDS) and tuberculosis(Direk Limmathurotsakul., et al 2010). In Taiwan a report says that there was a steady increase in the melioidosis cases between $1982-2000$ (Hsueh P et al 2001)

\section{Vibrio vulnificus}

Vibrio vulnificus is a gram negative motile curved shape bacteria. They are found in warm coastal regions, especially in the summer season when water become warmer. The bacteria can enter through wound or ingestion after an exposure to contaminated water. The clinical manifestation was redness and swelling of the wound followed by the sepsis. The symptoms include the fever, chills, diarrhea, nausea, vomiting, septic shock, and characteristic skin lesions, which include lower extremity cellulitis with ecchymosis and bullae, Because the organism can cross the intestinal mucosa rapidly, development of bullous skin lesions of the lower extremities, which are thought to be an early manifestation of sepsis, can occur within the first $24 \mathrm{~h}$ after onset of illness. (Klontz KC.,et al.1988) Although wound infection have been diagnosed in the healthy individual, the infection is mainly seen with the person whose immunity is impaired such as kidney disease, Diabetes, cancer etc. (Nicholas A. Daniels 2011). Iron is a predisposing factor for V. vulnificus where it used iron stores for bacterial growth, where the infection if found in the liver patients whose iron levels are elevated. (Haq SM, Dayal HH.,2005).

The first case of V. vulnificus was reported in 1970 with leg wound infection after exposure to New England Coastal water (Roland FP, 1970). They mainly causes wound infection, septicemia and diarrhea. The case history from US says that many cases have been reported due to the Vibrio Infection. According to Center for disease control and prevention 58 cases of Vibrio vulnificus has been reported in US between 1997 to 1998.A report by Chiang SR in 2003 says that in Taiwan there is a dramatic increase in the V. vulnificus infection with a history of dying within 48hrs of infection. From 1994-1996 the review report from Gulf Coast surveillance says that $45 \%$ of the infection is found to be wound and $43 \%$ of primary septicemia and $5 \%$ of gastrointestinal tract infection (Shapiro RL 1998).

\section{Edwardsiella tarda}

E.tarda was first described by Ewing et al in 1965, which is a gram negative anaerobic rods which measure ranging from 1 $\mu \mathrm{m}$ in diameter and 2-3 $\mu \mathrm{m}$ in length. They are the habitat of fresh water. It has been cultured directly from lakes, rivers, well and sewage water (Ellen M. Slaven et al 2001).Very rarely cases have been reported in Thailand and Taiwan. Cases has been reported with the marine exposures where it was identified mainly in warmer weather, from the month of May to October, which gives an evidence that increase proliferation can happen in warmer water or both (Ellen M. Slaven et al 2001).

A case report by Vartian CV in 1990 says that a 15 year old boy was infected with E.tarda while he was walking with bare foot in a fresh water lake and injured by submerged branch and he was found with progressive swelling and pain. A case 
was reported with Septicemia and Necrotizing Fasciitis for an old 62yrs Japanese male, who had diarrhea, swelling and erythema over the knee which developed into necrotic lesions. General symptoms are gastro enteritis which developed into ulceration and bleeding. E.tarda has reported to colonize the vagina where it is potential source of neonatal sepsis through exposure at birth. In 2002 it was reported that a pregnant women who had spent time in lake, later the infection was found in the new born baby (Mowbray EE et al 2002). Before 2003 the E.tarda infection was very rare with a reported case of 2 but later rate increased to 300 in which water was the main source of infection with a prevalence in Singapore, Vietnam and Cuba. V Manchanda 2006 reported a case of liver abscess which was caused by E.tarda and the source of infection was ruled out to be the exposure to pond water.

\section{Sphingomonas paucimobilis}

Sphingomonas paucimobilis was first discovered to cause human infection in 1977 and was named has Pseudomonas paucimobilis.(Mehmet Özdemir et al 2011). They are non fermenting gram negative bacteria which is responsible for the nosocomial infections. They are normally found in aquatic environment such has drinking water system, mineral water, water equipment used in hospitals, river water, waste water, distilled water, dialysis fluid can be a water borne clinical pathogens which is for hospital infection especially in immuno compremised patients. (Calubiran et al., 1990; Morrison \& Shulman, 1986; Reina et al., 1991,I-Ching Kuo et al 2009) The major drawback is this bacteria is capable of forming bio film in water pipe line connections. They are associated with clinical symptoms such as bacteremia, pneumonia, catheter related infections, meningitis, peritonitis, osteomyelitis, septic arthritis, postoperative endophthalmitis, lung emphysema, splenic abscesses, urinary tract infections, and biliary tract infections.

Between October 2008 - November 200815 cases of neonatal infection has been reported due to S.paucimobilis and major source of infection id distilled water which is used for humidifying of incubators and mechanical ventilator. (Mehmet Mutlu., 2010).

\section{Francisella tularensis}

F. tularensis are non motile gram negative cocco bacilli, nonmotile, and appears as small approximately $0.2-0.5 \mu \mathrm{m}$ by 0.7-1.0 $\mu \mathrm{m}$ (Ellis $\mathrm{J}$ et al., 2002). A spanish outbreak of 19 case was reported due to the contact of river caught cray fish. (Anda P et al 2001).The same report says there was about 1091 cases of Tularemia cases between 2005 - 2008 in Turkey. Saban Gurcan reported 8 cases of Tularemia in children who had an history of swimming in a pool filled with water from local stream and contact with stream water. A survey of small tularemia outbreak in a village of Karamursel county of Kocaeli province was done in between January 2005 - March 2005 where 17 patients was diagnosed with tularemia where the age group was between $27-80 y$ rs in that $59 \%$ was female and symptoms varied from person to person with weakness, swelling on the neck $(94 \%)$, sore throat $(88 \%)$. The reason for outbreak was later ruled out to be natural spring water. (Meric M, 2008). Later in Nov 2009 - December 2009 investigation was done in the same village for water borne out break of tularemia, 14 cases was identified with 11 cases of Oropharyngeal tularemia, 3 cases of glandular form and 1 case in pneumonic form. Where the source was ruled out to be natural spring water.( Ulu Kılıc A 2011). In March 198249 cases of oropharyngeal tularemia in Italy due to water system. (Greco D et al 1987).

\section{Stenotrophomonas maltophilia}

Stenotrophomonas maltophilia are aerobic gram negative bacteria measure approximately $0.7-1.8 \times \quad 0.4-0.7$ micrometers.S. Maltophilia is an environmental bacterium found in aqueous habitat, including plant rhizopheres, animals, food and water sources.(Joanna S. Brooke 2012 ) S. maltophilia is found among the hetrotropic plate count in the natural potable water. (Rusin PA et al 1997). The most common sites of contamination were sink drains, faucets, and other items frequently in contact with water. (Denton $\mathrm{M}$ et al 1998). An outbreak due to s. maltophilia was reported at NICU where infant was infected and the source was ruled out to be the tap water was used to wash the preterm infants (Verweij PE 1998). A paint company in the state of Paraná in Brazil had several batches of water-based acrylic paints contaminated with microorganisms, which was identified as Stenotrophomonas maltophilia (Fernanda Rochoel La Rosa et al 2008).

\section{Plesiomonas shigelloides:}

Plesiomonas shigelloides anaerobic gram negative with size ranging from 0.3-1.0 $\mu \mathrm{m}$ in width, 0.6-6.0 $\mu \mathrm{m}$ in length. The organism was first isolated by Ferguson and Henderson in 1947. They can survive at wide range of $\mathrm{pH}$ and temperature such has $\mathrm{pH}$ ranging from $4-8$ and temperature ranging from $8-44^{\circ} \mathrm{C}$. The mode of transmission is mainly through the faeco oral, consumption of infected sea food, contaminated water. A survey was done by Teruyoshi Arai et al in 1980 to isolate Plesiomonas shigelloides which showed $3(0.0078 \%)$ of 38454 healthy Tokyoites, $37(3.8 \%)$ of 967 dogs, 40 $(10.3 \%)$ of 389 cats, $25(10.2 \%)$ of 246 fresh water fish, $64(12.8 \%)$ of 497 river water samples, and 2 of $19(10.5 \%)$ sludge samples.

\section{Discussion:}

Water can be a source of infection, it can be a direct exposure or indirect. This can be avoided by proper care. In many cases the hospital aquired infection is through the negligance which takes hundreds of life. In the current report most of the cases has been reported very rarely, but in the mere future these names willbe replaced by new microbes by making them the general infections. 


\section{REFERENCES}

1. Air Vice-Marshal., Bruce,H., Short,A. 2002: Melioidosis: An important emerging infectious disease a militaryproblem? ADF Health Vol 3

2. Alexander von Graevenitz., John Bowman.,Carlo Del Notaro.,\& Michael Ritzler. 2000. Human Infection with Halomonas venusta following Fish Bite. Journal of Clinical Microbiology. 38(8): 3123-3124.

3. Alfred,M.Emmerson. 2001. Emerging Waterborne Infections in Health-Care Settings.Emerging Infectious Diseases. Vol. 7, No. 2.

4. Annette,C.,Rebolit \& W, Edmund Farrar.1989. Erysipelothrix rhusiopathiae: An Occupational Pathogen. Clinical Microbiology Reviews, 354-359.

5. Arsonson,J.D.1926. Spontaneous tuberculosis in salt water fish. Journal of Infectious Disease. 39:315-20.

6. Aslani, M.M., and Alikhani, M.Y. 2004: The role of Aeromonas hydrophila in diarrhea. Iranian Journal of Public Health 33( 3): 54-59.

7. Atapattu, D.N., Jayawickrama, D.P.,Thevanesam, V. 2001. An unusual bacterium causing a brain abscess. Emerging Infectious Disease.7: 159-160.

8. Anda,P., Segura del Pozo,J., Diaz Garcia,J.M., et al. 2001. Waterborne outbreak of tularemia associated with crayfish fishing. Emerging Infectious Disease.;7(3 Suppl):575-582.

9. Baumann,L., Baumann, P., Mandel .M., Allen,R.D. 1972.Taxonomy of aerobic marine bacteria. Journal of Bacteriology.110:402-429.

10. Baumann,L., Bowditch,R.D., Baumann,P. 1983.Description of Deleya gen. nov. created to accomodate the marine species Alcaligenes aestus, A. pacificus, A. cupidus, A. venustus, and Pseudomonas marina. International Journal of Systemic bacteriology.33:793-802.

11. Brown,T.H.,1985.The rapidly growing mycobacteria-Mycobacterium fortuitum and Mycobacterium chelonei. Infect Control.6: 283-288.

12. Calubiran, O. V., Schoch, P. E. \& Cunha, B. A. 1990. Pseudomonas paucimobilis bacteremia associated with haemodialysis. Journal of Hospital Infection..15, 383-388.

13. Chiang,S.R., Chuang,Y.C.2003. Vibrio vulnificus infection: clinical manifestations, pathogenesis, and antimicrobial therapy. Journal of Microbiology, Immunology and Infection. 36(2):81-8.

14. I-Ching, Kuo., Po-Liang Lu., Wei-Ru Lin., Chun-Yu Lin., Yu-Wei Chang., Tun-Chieh Chen \& YenHsu Chen`2009. Sphingomonas paucimobilis bacteraemia and septic arthritis in a diabetic patient presenting with septic pulmonary emboli.Journal of Medical Microbiology. vol. 58 no. 9 1259-1263.

15. Dean Campbell., Mark Cowan.2013. Septicemia and Aortic Valve Endocarditis due to Erysipelothrix rhusiopathiae in a Homeless Man Case Reports in Infectious Diseases. Article ID 923034, 4 pages.

16. Denton,M., Todd,N.J., Kerr,K.G., et al.1998.Molecular epidemiology of Stenotrophomonas maltophilia isolated from clinical specimens from patients with cystic fibrosis and associated environmental samples. Journal of Clinical Microbiology.36:1953-8

17. Direk Limmathurotsakul., Surasakdi Wongratanacheewin., Nittaya Teerawattanasook., Gumphol Wongsuvan, Seksan Chaisuksant, Ploenchan Chetchotisakd, Wipada Chaowagul, Nicholas P.J. Day, and Sharon J. Peacock. 2010. Increasing Incidence of Human Melioidosis in Northeast Thailand. The American Journal of Tropical Medicine and Hygiene. 82(6): 1113-1117.

18. Ellen,M., Slaven, Fred A., Lopez., Shana M., Hart and Charles, V., Sanders.,2001.Myonecrosis Caused by Edwardsiella tarda: A Case Report and Case Series of Extraintestinal E. tarda Infections. Clinical Infectious Disease.32 (10): 1430-1433.

19. Elko, L.E.,K.Rosenbach, \& J.Sinnott.2004.Cutaneous manifestations of waterborne infections. Current Infectious Disease Reports 5: 398-406.

20. Ender,P.T., Dolan,M.J.,1997.Pneumonia associated with near-drowning. Clinical Infectious Disease.25: 896-907.

21. Ellis,J., Oyston,P.C., Green,M., Titball,R.W. 2002.Tularemia. Clinical Microbiology Review 15:631-646.

22. Ellen,M., Slaven.,Fred,A. Lopez., Shana,M. Hart \& Charles,V., Sanders.2001.Myonecrosis Caused by Edwardsiella tarda: A Case Report and Case Series of Extraintestinal E. tarda Infections. Clinical Infectious Disease .32 (10): 1430-1433.

23. Ewing, W. H.,Mcwhorter, A. C., Escobar, M. R., Lubin, A. H. 1965. Edwardsiella, a new genus of 
Enterobacteriaceae based on a new species, E. tarda. International Bulletin of Bacteriological Nomenclature and Taxonomy 15 (1): 33-38.

24. Feng $\mathrm{Y}, \mathrm{Xu} \mathrm{H}$, et al. 2011. Outbreak of a cutaneous Mycobacterium marinum infection in Jiangsu Haian, China. Diagnostic Microbiology and Infectious Disease.71 (3): 267-72.

25. Fernanda Rochoel La Rosa.,Ellen Cristine Giese.,Robert Frans Huibert Dekker.,Jacinta Sánchez Pelayo.,Aneli de Melo Barbosa.2008. Microbiological contamination of water-based paints from an industry in the state of Paraná, Brazil.Semina: Ciencias Exatas e da Terra, Londrina, v. 29, n. 1, p. 85-92.

26. Ferguson,W.W., Henderson,N.D.1947. Description of strain C27: A motile organism with the major antigen of Shigella sonnei phase 1. J Bacteriol. 54:179-81.

27. Gunther Slesak.,Phouvieng Douangdala,Saythong Inthalad., Joy Silisouk,Manivanh Vongsouvath.,Amphonesavanh Sengduangphachanh.,Catrin E Moore.,Mayfong Mayxay., Hiroyuki Matsuoka,and Paul N Newton. 2009. Fatal Chromobacterium violaceum septicaemia in northern Laos, a modified oxidase test and post-mortem forensic family G6PD analysis. Annals of Clinical Microbiology and Antimicrobials .8: 24.

28. Greco,D., Allegrini,G., Tizzi,T., Ninu,E., Lamanna,A., Luzi,S.1987.A waterborne tularemia outbreak. European Journal of Epidemiology.3:35-38

29. Harry Philippeaux, Pan American Health Organization, Office of the Caribbean, Program Coordination in Barbados Emerging Water Borne Pathogens.

30. H-C. Wang., Y-S. Liaw., P-C. Yang., S-H. Kuo., K-T. Luh.1995.A pseudoepidemic of Mycobacterium chelonae infection caused by contamination of a fibreoptic bronchoscope suction channel. European Respiratory Journal. 8(8):1259-62.

31. Hildy Meyers.,Barbara,A., Brown-Elliott., \& Richard,J., Wallace. 2002 An Outbreak of Mycobacterium chelonae Infection Following Liposuction, CID:34.

32. Hagedorn,M., Rohde,K.H., Russell,D.G., Soldati,T.I.2009 March. Infection by tubercular mycobacteria is spread by nonlytic ejection from their amoeba hosts. Science. 27;323(5922):1729-33.

33. Hsueh.P., Teng,L., Lee L, et al. 2001. Melioidosis, an emerging infection inTaiwan? Emerging Infectious Disease. 7: 428-432.

34. Haq,S.M., Dayal,H.H.2005. Chronic liver disease and consumption of raw oysters: a potentially lethal combination A review of Vibrio vulnificus septicemia.American Journal of Gastroenterology.100:1195-9.

35. Joanna,S.,Brooke.2012 Stenotrophomonas maltophilia: An Emerging Global Opportunistic Pathogen. Clinical Mocrobiology Reviews.vol. 25 no. $12-41$

36. Koch, R. 1880. Investigations into the etiology of traumatic infective diseases. New Sydenham Society, London.

37. Kenji Okumura.,Fumihiro Shoji., Masaki Yoshida., Atsushi Mizuta., Ichiro Makino and Hidefumi Higashi.2011. Severe sepsis caused by Aeromonas hydrophila in a patient using tocilizumab: a case report .Journal of Medical Case Reports 5:499.

38. Khardori,N., Fainstein,V. 1988. Aeromonas and Plesiomonas as etiological agents. Annual Review of Microbiology.42, 395.

39. Klontz, K. C., Lieb, S., Schreiber, M., Janowski, H. T., Baldy, L. M., Gunn, R. A. 1988. Syndromes of Vibrio vulnificus infections: clinical and epidemiologic features in Florida cases, 1981-1987. Annals of Internal Medicine.109:318-23.

40. Louis,H.Nel \& Wanda Markotter ., New and emerging water borne infectious disease water and health vol I.

41. Lee.J, J. S. Kim, C. H. Nahm, J. W. Choi,1 J. Kim,S. H. Pai,K. H. Moon,K. Lee, and Y. Chong. 1999. Two Cases of Chromobacterium violaceum Infection after Injury in a Subtropical Region Journal of Clinical Microbiology. 37(6): 2068-2070.

42. Mark ,N Schwendiman, Ryan P Johnson MD MPH'J Scott Henning.2009'Subcutaneous nodules with sporotrichoid spread Dermatology Online Journal 15 (5): 11

43. Meyers et al. Douglas Moore.2002.County of Orange Health Care Agency/Public Health, Santa Ana, California;Curry, Cecile Truong. An Outbreak of Mycobacterium chelonae Infection Following Liposuction. CID:34

44. Mehmet Özdemir, Sevgi Pekcan, Mehmet Emin Demircili, Fatma Esenkaya Taşbent, Bahadır Feyzioğlu, Şerife Pirinç, Mahmut Baykan. 2011. A Rare Cause of Bacteremia in a Pediatric Patient with Down Syndrome: Sphingomonas Paucimobilis. Int J Med Sci. 8(7):537-539

45. Midani,S., Rathore,M.1998.Chromobacterium violaceum infection. Southern Medical Journal. 91: 464-6.

46. Meriç,M.,Sayan,M.,Willke,A.,Gedikoğlu,S.2008.A small water-borne tularemia outbreak, Mikrobiyol Bul.;42(1):4959 
47. Palumbo, S. A., F. Maxino, A. C. Wiliams, R. L. Buchanan, andD. W. Thayer. 1985. Starch-ampicillin agar for the quantitative detection of Aeromonas hydrophila. Applied and Environmental Microbiology. 50:1027-1030.

48. Mamatha Ballal, Pushpa Kini, D. Rajeshwari, P. G. Shivananda.2000.Chromobacterium violaceum diarrhea The Indian Journal of Pediatrics .Volume 67, Issue 5, pp 388-389.

49. Martinez R, Velludo MASL, Santos VR, Dinamarco, PV.2000.Chromobacterium violaceum infection in Brazil.A case report. Rev Inst Med Trop Sao Paulo.42(2):111-3.

50. Mowbray EE, Buck G, Humbaugh KE, Marshall GS. 2003. Maternal colonization and neonatal sepsis caused by Edwardsiella tarda.Pediatrics.;111(3):e296-8.

51. Manchanda.V Manchanda, NP Singh, HK Eideh, A Shamweel, SS Thukral.2006.Liver Abscess caused by Edwardsiella tarda biogroup 1 and identification of its Epidemiology triad by ribotyping .Indian Journal of Medical Microbiology.24 (2):135-7.

52. Morrison, A. J., Jr \& Shulman, J. A.1986.Community-acquired bloodstream infection caused by Pseudomonas paucimobilis: Case report and review of the literature. Journal of Clinical Microbiology. 24, 853-855.

53. Mehmet Mutlu, Gülçin Bayramoglu, Gürdal Yilmaz, Berna Saygin and Yakup Aslan.2011. Outbreak of Sphingomonas paucimobilis Septicemia in a Neonatal Intensive Care Unit.Indian Pediatrics.48: 723-725.

54. Nicholas A. Daniels.2011.Vibrio vulnificus Oysters: Pearls and PerilsCID: 52 Food Safety.

55. Orsetti AG, Markiewicz P, Epstein MG, Conceição OJG, D’lppolito G, Ribeiro MAF. 2013 . Liver abscesses by Chromobacterium violaceum: A case report of a rare disease. OA Case Reports.28;2(2):19.

56. Palmera-Suarez, R., Garcia, P., Garcia, A., Barrasa, A. and Herrera, D.2007.Salmonella Kottbus outbreak in infants in Gran Canaria (Spain) caused by bottled water, . Eurosurveillance12 (28).

57. Rees JC, Alten KD. 1996. Holy water-A risk for hospital-acquired infection. Journal of Hospital Infection.32:515.

58. Roberts SA, Morris AJ, Mclvor N, Ellis-Pegler R. 1997. Chromobacterium violaceum infection of the deep neck tissues in a traveler to Thailand. Clinical Infectious Disease.25: 334-5.

59. Rusin PA, Rose JB, Haas CN, et al.1997.Risk assessment of opportunistic bacterial pathogens in drinking water. Reviews of environmental contamination and toxicology.152:57-83.

60. Ramona Simionescu, MD, Sandeep Grover, MD, Raja Shekar, and Burton C. West, MD.2003. Necrotizing Fasciitis Caused by Erysipelothrix rhusiopathiae. South African Medical Journal.96(6).

61. Rimington RA.1962.Melioidosis in Northern Queensland. Medical Journal of Australia.1:50-53.

62. Roland FP. 1970 Leg gangrene and endotoxin shock due to Vibrio parahaemolyticus: an infection acquired in New England coastal waters. New England journal of medicine_.282:1306.

63. Sanders, Jr., W. E., and Horowitz, E. A. 1990. Other Mycobacterium species, p. 1914-1926. In G. L. Mandel, R. G. Douglas, Jr., and J. E. Bennett (ed.), Principles and practice of infectious disease. Churchill, Livingston, New York.

64. Schubert, R.H.W.1975. The relationship of aerogenic and anaerogenic aeromonads of the "hydrophila and puncata group' in river water depending on the load of waste. Zentralblat fuer Bakteriologie, Mikrobiologie und Hygiene 160,237-245.

65. Sneath PHA, Whelan JPF, Singh RB, Edwards D. 1953.Fatal infection by Chromobacterium violaceum. Lancet.2: 276-7.

66. Shou-Wu Lee, Che-AnTsai1, Bor-Jen Lee.2008. Chryseobacterium meningosepticum Sepsis Complicated with Retroperitoneal Hematoma and Pleural Effusion in a Diabetic Patient Intestive Care Unit Journal of the Chinese Medical Association. Vol 71 No 9

67. Caputo, V.; Fiorella, S.; Orlando, E.2010.Clinical Medicine Insights: Sporotrichoid Cases of Mycobacterium Marinum Skin Infection.Dermatology. Issue 3, p25.

68. Shapiro RL, Altekruse S, Hutwagner L, et al. 1998 The role of Gulf Coast oysters harvested in warmer months in Vibrio vulnificus infections in the United States. Journal of Infectious Disease.178:752-9.

69. S.Gurcan,G.Varol Saracoglu, A.Karadenzli,E. N.Ozkayin, S. Z. Ozturk, C. Cicek, B. Vatansever 2012 .Tularemia as a result of outdoor activities for children in the countryside. Turkish Journal Of Medical Science.42 (6): $1044-$ 1049

70. Ti TY, Tan WC, Chong AP, Lee EH.1993.Nonfatal and fatal infections caused by Chromobacterium violaceum. Clinical Infectious Disease.17: 505-7.

71. Teruyoshi Arai, Nobuyuki Ikejima, Takeshi Itoh, Senzo Sakai, Toshio Shimada and Riichi Sakazaki 1980. Journal of Hygiene / Volume 84 / Issue 02 , pp 203-211. 
72. Ulu Kılıç A, Kılıç S, Sencan I, Ciçek Şentürk G, Gürbüz Y, Tütüncü EE, Celebi B, Kıcıman Ö, Ergönül Ö.2011.A water-borne tularemia outbreak caused by Francisella tularensis subspecies holarctica in Central Anatolia region,Mikrobiyol Bul.45(2):234-47

73. Van Seymortier P, Verellen K, De Jongel.2004. Mycobacterium marinum causing tenosynovitis. 'Fish tank finger. Acta orthopaedica Belgica Journal. 70:279-282.

74. Verweii PE, Meis JF,Christmann V,Van der Bor M, Melchers WJ, Hilderink BG, Voss A. 1998. Nosocomial outbreak of colonization and infection with Stenotrophomonas maltophilia in preterm infants associated with contaminated tap water.Epidemiol Infect.120(3):251-6.

75. Vartian CV, Septimus EJ.1990.Soft-tissue infection caused by Edwardsiella tarda and Aeromonas hydrophila .Journal of Infectious Disease.161:816.

76. Wooley PG. 1905 Bacillus violaceum manilae (a pathogenic organism). Bull Johns Hopkins Hosp.;16: 89.

77. R. L. Wood, W. T. Hubbert, W. F. McCullough, P. R. Schnurrenberger, and C. C. Thomas, Eds.975. "Erysipelothrix infection," in Diseases Transmitted From Animals to Man, pp. 271-281, Springfield, III, USA, 6th edition.

78. Whitmore A, Krishnaswami CS. 1912.An account of the discovery of a hitherto undescribed infective disease occurring among the population of Rangoon. Indian medical gazette .47: 262-267.

79 Wirongrong Chierakul, Wut Winothai, Charnkij Wattanawaitunechai, Vanaporn Wuthiekanun, Thaweesak Rugtaengan, Jurairat Rattanalertnavee, Pornlert Jitpratoom, Wipada Chaowagul, Pratap Singhasivanon, Nicholas J. White, Nicholas P. Day, and Sharon J. Peacock.2005. Melioidosis in 6 Tsunami Survivors in Southern Thailand.Clinical InfectiousDisease.41(7):982-990.doi:10.1086/432942. 